\title{
Síndrome de Down Versus Alteração de Linguagem: Interaçáo Comunicativa Entre Pais e Filhos ${ }^{1}$ DOWN SyNdRome Versus LANGUAGE Disorder: COMMUNICATIVE INTERACTION BETWEEN PARENTS AND CHILDREN
}

\author{
Maria Grazia Guillen MAYER ${ }^{2}$ \\ Maria Amelia ALMEIDA ${ }^{3}$ \\ Simone Aparecida LOPES-HERRERA ${ }^{4}$
}

\begin{abstract}
RESUMO: é preciso interagir com outros seres humanos como meio de sobrevivência, proteção e estimulação, sendo que a comunicação nasce desta necessidade. A comunicação pode ser realizada por meio de códigos linguísticos e náo-linguísticos e envolvem, no mínimo, duas pessoas (interlocutores), que trocam entre si uma mensagem qualquer. O objetivo do presente estudo foi investigar a interação de mães de crianças com síndrome de Down e seus filhos e mães de crianças com alteração de linguagem e seus filhos. Foram participantes da pesquisa cinco díades de crianças com síndrome de Down e suas mães e cinco díades de crianças com atraso de linguagem e suas mães. Foram gravadas três sessōes de interação espontânea de mãe e criança em ambiente domiciliar. Os resultados mostraram que mães de crianças com atraso de linguagem apresentaram comportamentos mais adequados na interação com seus filhos, tais como equilíbrio da atividade dialógica durante a interação, estrutura gramatical e complexidade do discurso adequado, mais paciência com a criança e adequada entonaçáo da fala. Por outro lado, mães de crianças com síndrome de Down demonstraram mais interesse durante a interaçấo comunicativa.
\end{abstract}

PALAVRAS-CHAVE: Interação Social. Alteração de Linguagem. Síndrome de Down. Comunicação.

ABSTRACT: Interacting with other human beings is necessary for survival, protection and stimulation - and communication emerges out of necessity. Communication can be accomplished through linguistic and non-linguistic codes involving, at least, two people, classified as interlocutors, who exchange messages between each other. The aim of this study was to investigate interaction between mothers with Down syndrome children and their children and mothers with children with language disorders and their children. Five dyads of Down syndrome children and their mothers, and five dyads of children with language disorders and their mothers participated in the study. Three sessions of spontaneous interaction between mother and child were recorded at home. The results showed that the behaviors of mothers of children with language disorders were more appropriate when interacting with their children. They showed greater balance of dialogic activity during interaction, better grammatical structure and greater complexity of proper speech, more patience with the child and proper speech intonation. For their part, the mothers of children with Down syndrome showed greater interest during communicative interaction.

KEYWORDS: Social interaction. Language Disorder. Down syndrome. Communication.

\section{INTRODUÇÃo}

O desejo de se expressar é vital e se origina dos esforços do ser humano em satisfazer suas necessidades de ordem física e emocional. É necessária a interação com outros seres humanos como meio de sobrevivência, proteção e estimulação - e a comunicação nasce desta necessidade. A comunicação envolve uma série de fatores que podem ser observados e identificados, embora ocorra de forma natural, espontânea e inconsciente. Pode ser realizada através de códigos linguísticos (fala, escrita, língua de sinais) e não-linguísticos (expressóes

${ }^{1}$ APOIO: FAPESP- Fundação de Amparo à Pesquisa do Estado de São Paulo.

${ }^{2}$ Mestre em Educação Especial, Doutoranda em Educação Especial, Universidade Federal de São Carlos. mggmayer@hotmail.com

${ }^{3}$ Professora Doutora do Programa de Pós Graduação em Educação Especial, Universidade Federal de São Carlos. ameliama@ terra.com.br

${ }^{4}$ Professora Doutora do Departamento de Fonoaudiologia da Faculdade de Odontologia de Bauru da Universidade de São Paulo. lopesimone@usp.br 
faciais, sorrisos, olhares, toques e "silêncios"), e envolvem, no mínimo, duas pessoas, classificadas como interlocutores, que trocam entre si uma mensagem qualquer (SYDER, 1997; LOPES 2000; LOPES-HERRERA, 2004).

A comunicação requer habilidades básicas, como a capacidade para iniciar, interagir, responder apropriadamente ao que está sendo questionado, além de manter a interação. As habilidades de interação verbal são o centro das teorias de desenvolvimento de linguagem no contexto social. Durante a interação social, as crianças aprendem como usar a linguagem e fazer dela uso social. Hadley e Rice (1991) sugerem que dificuldades na interação podem ser consequência de alteraçóes de linguagem.

Lemes, Lemes e Goldfeld (2006) investigaram, por meio da análise da brincadeira simbólica, como o comportamento materno influencia no desenvolvimento da linguagem infantil e refletiram sobre a relevância da orientação fonoaudiológica, sendo esta considerada importante para a mudança da postura materna e, consequentemente, ao efetivo processo de construção de linguagem infantil.

Segundo a Commitee for Children and Youths with Communication Disorders (1996), as desordens da comunicação são impedimentos na habilidade para receber e/ou processar um sistema simbólico, observáveis em nível de audição, linguagem e processos de fala. Essas desordens podem variar em grau de severidade, serem de origem desenvolvimental ou adquirida, resultarem numa condição de déficit primário (patologias de manifestação primária ou idiopatias) ou secundário (patologias de manifestação secundária, decorrentes de uma patologia maior) e, ainda, ocorrerem isolada ou combinadamente. Um dos tipos de desordens da comunicação é aquele relacionado às alteraçóes da linguagem, acarretando prejuízos na forma, no conteúdo e/ou na função comunicativa.

A síndrome de Down é a causa genética mais comum de déficit intelectual (YODER; WARREN, 2004). Määttä et al. (2006), Silva e Kleinhans (2006) consideram que as alteraçóes das habilidades cognitivas na síndrome de Down são uma consequência primária, e aparecem como resultado de anormalidades estruturais e funcionais do sistema nervoso central. Essas alteraçóes também influenciam nas relaçóes que a criança estabelece no seu ambiente, pressupondo, dessa forma, que a criança atue mais passivamente no meio em que está inserida.

O desenvolvimento cognitivo da criança com síndrome de Down é superior ao desenvolvimento da linguagem, sendo a compreensão mais efetiva que a expressão; por isso, a linguagem não-verbal exerce uma função importante na comunicação destas crianças. Os acometimentos motores orais, como a hipotonicidade, contribuem para a ininteligibilidade da fala, os déficits de memória de curto-prazo e processamento auditivo relacionam-se com as outras dificuldades e as condiçóes de desenvolvimento global e ambiental devem sempre ser consideradas (ANDRADE; LIMONGI, 2007; SCHWARTZMAN, 1999).

Supondo-se que haja uma relação direta entre desenvolvimento cognitivo e construção da linguagem e que para que ambas ocorram de forma adequada e efetiva haja necessidade de um organismo com suas plenas possibilidades, vivendo em um meio que lhe garanta a realização destas, é claramente delineada a condição de construção de linguagem e de sua expressão na linguagem da criança com síndrome de Down (LIMONGI, 2004). 
Visto que a mãe é mediadora das ações da criança com o ambiente, Gomes, Andrade e Limongi (1992) consideram a interação mãe-criança como uma fonte importante de estímulos cognitivos e linguísticos durante o período de aquisição de linguagem. A falta de estímulos adequados durante a interação mãe e criança com síndrome de Down pode ser significativa para o desenvolvimento da criança.

Limongi (2004) conclui que a efetividade da interação mãe e criança com síndrome de Down diz respeito a dois fatores: à compreensão das dificuldades da criança e do seu potencial e à compreensão de um processo terapêutico proposto para efetivar essa interação. À medida que as mães melhoram a interação com seus filhos, estes passam a responder mais e melhor aos estímulos oferecidos e, como consequência, as mães se sentem mais dispostas a estimulá-los e tornam-se autoconfiantes no lidar com os filhos, o que facilita a percepção dos progressos nas áreas do desenvolvimento global que eles adquirem.

Ferreira e Lamônica (2012) verificaram o desempenho lexical, receptivo e expressivo de crianças com síndrome de Down e compararam com o desempenho de crianças com desenvolvimento típico pareados por sexo e idade intelectual. Os resultados mostraram que crianças com síndrome de Down apresentam desempenho inferior a crianças com desenvolvimento típico, com diferenças estatisticamente significantes no desempenho lexical, tanto expressivo quanto receptivo, mesmo quando comparadas com a idade intelectual.

Silva e Kleinhans (2006) concluíram que, ao conhecer as alterações inerentes à síndrome de Down, pode-se compreender que a capacidade do organismo humano em se adaptar ao meio e à plasticidade cerebral está relacionada à qualidade, duração e forma de estimulação que recebe o indivíduo com a síndrome, ou seja, falar em plasticidade na síndrome de Down implica em considerar o ecossistema em que a pessoa está inserida; além disso a inserção da família como parte ativa no tratamento é de suma importância e, atualmente, não se concebe um atendimento fragmentado. Para que se possam minimizar os fatores de risco, a família, a escola e os profissionais (médicos, psicólogos, professores, fisioterapeutas, fonoaudiólogos, dentre outros) devem unir forças num trabalho coeso (SILVA; KLEINHANS, 2006).

A família é o primeiro lugar onde a criança irá estabelecer seus vínculos, deduz-se que é também dela que receberá seus primeiros estímulos. Sendo assim, é necessário que os pais estejam preparados e saibam a maneira de proporcionar os melhores estímulos a essas crianças. Pelo exposto, este estudo teve como objetivo investigar a interação de pais de crianças com síndrome de Down e seus filhos e de pais de crianças com alteração de linguagem e seus filhos.

\section{Método}

Todos os procedimentos foram devidamente submetidos e aprovados pelo Comitê de Ética em Pesquisa da Universidade Federal de São Carlos, sob o parecer no 373/2008.

\subsection{Participantes}

Participaram desta pesquisa 10 díades mãe e criança sendo: 5 crianças com alteraçóes de linguagem na faixa etária de 4 a 8 anos e suas respectivas mães e outras 5 com diagnóstico médico de síndrome de Down, na faixa etária de 6 a 10 anos de idade e suas respectivas 
mães. A diferença de idade deve-se à alteração cognitiva e, consequentemente, de linguagem, encontrada em crianças com síndrome de Down.

\subsection{LOCAL}

As gravaçóes ocorreram na residência da criança, ou seja, no ambiente mais natural possível, num local sem estímulos visuais ou auditivos que pudessem prejudicar a comunicação. O local foi previamente preparado pela pesquisadora com materiais pré-selecionados para a realização das atividades e que promovessem a interação. Foram selecionados os seguintes brinquedos e objetos: massa de modelar, quebra-cabeça, livro de estórias, papel sulfite, giz de cera e dois jogos interativos, um deles em que a criança deveria sortear e então encontrar cópias da figura em um tabuleiro e outro em que o objetivo era martelar alguns blocos de plásticos e não deixar que o bichinho caísse.

\subsection{Coleta dos dados}

Foram realizadas 3 sessões de interação mãe-filho por meio de gravação em filmadora digital, as interaçôes foram feitas em dias diferentes e com cada díade separadamente. Essas interaçóes ocorreram por meio de atividades lúdicas de 30 minutos cada gravaçáo, com no mínimo uma semana de diferença entre as gravaçóes; optou-se por 30 minutos de gravação pelo fato de que as análises interacionais e de comunicação/linguagem tomam por base corpus linguísticos desta magnitude, principalmente quando se tratam de situaçóes ricas em dados como as de interação espontânea (BRETANHA; LOPES-HERRERA, 2012). As sessóes foram filmadas e posteriormente gravadas em DVD. A pesquisadora explicava o procedimento aos participantes, retirando eventuais dúvidas e, em seguida, saía da sala, para que dessa forma a interação fosse a mais natural possível, retornando após 30 minutos. A mesma caixa de brinquedos era disponibilizada a todos os participantes.

\subsection{ANÁlISE DOS DADOS}

Para análise das gravações foram utilizados dois protocolos elaborados pela própria pesquisadora, utilizando como base os seguintes autores: Zorzi (1999), Andrade et al. (2004) e Lopes-Herrera et al. (2009). Os Protocolos foram chamados de "Observação dos Comportamentos Comunicativos Verbais e Não-Verbais do Adulto em Relação à Criança” e continham questôes relacionadas à explicação das regras do jogo, domínio da conversação, interesse pela atividade realizada, forma discursiva utilizada, complexidade e vocabulário do discurso, fornecimento de técnicas para melhora da comunicação e entonação usada pelo adulto com a criança, fatores esses necessários a um efetivo desenvolvimento da linguagem.

Osegundo protocolo denominado "Observação dos Comportamentos Comunicativos Verbais e Não-Verbais da Criança em Relação ao Adulto” continha questóes sobre compreensão das regras do jogo, domínio da conversação, complexidade e vocabulário do discurso, interesse pelas atividades realizadas e entonação de fala.

Para que não houvesse dúvidas e divergências durante o preenchimento dos protocolos, todas as categorias foram detalhadamente descritas e padronizadas, e então submetidas a 
quatro juízas, especialistas na área da linguagem, as quais tiveram oportunidade de ler e sugerir eventuais alteraçóes. Após revisão feita pela pesquisadora, os protocolos retornaram para as juízas que aprovaram em seguida.

As 30 gravações realizadas foram assistidas e analisadas, dessa vez por dois juízes, para cálculo da concordância interobservadores, que preencheram o protocolo de observação após lerem e tomarem conhecimento sobre as categorias descritas anteriormente. $\mathrm{O}$ cálculo de concordância foi realizado ponto a ponto, sendo que - para cada categoria observada foi realizado o registro do comportamento, para que dessa forma fosse possível calcular a concordância interobservadores e garantir a fidedignidade dos dados. Para cada gravação, a concordância interobservadores de cada categoria analisada deveria ser de $75 \%$ ou mais. Esse parâmetro foi obtido segundo a fórmula de Barlow e Hersen (1984). Ressalta-se que nesse estudo a concordância para todas as categorias analisadas foi igual ou superior a $80 \%$.

\section{Resultados E discussóes}

Abaixo se encontram as figuras com os resultados de acordo com os achados comportamentais observados durante as gravaçóes. É necessário esclarecer que os números descritos nas tabelas referem-se a uma pessoa da díade, lembrando que participaram cinco díades de mãe e criança com síndrome de Down e cinco díades de mãe e criança com alterações de linguagem. Dessa forma, o eixo vertical representa o número de adultos ou de crianças.

Assim, por exemplo, a Figura 1 (Fornecimento de regras e instruçóes pelo adulto) mostra que na primeira gravação somente uma mãe de criança com síndrome de Down e outra mãe de criança com alterações de linguagem conseguiram fornecer instrução clara e objetiva, enquanto três mães de crianças com síndrome de Down e uma mãe de criança com alterações de linguagem não conseguiram fornecer as instruções.

Figura 1 - Fornecimento de regras e instruçóes pelo adulto

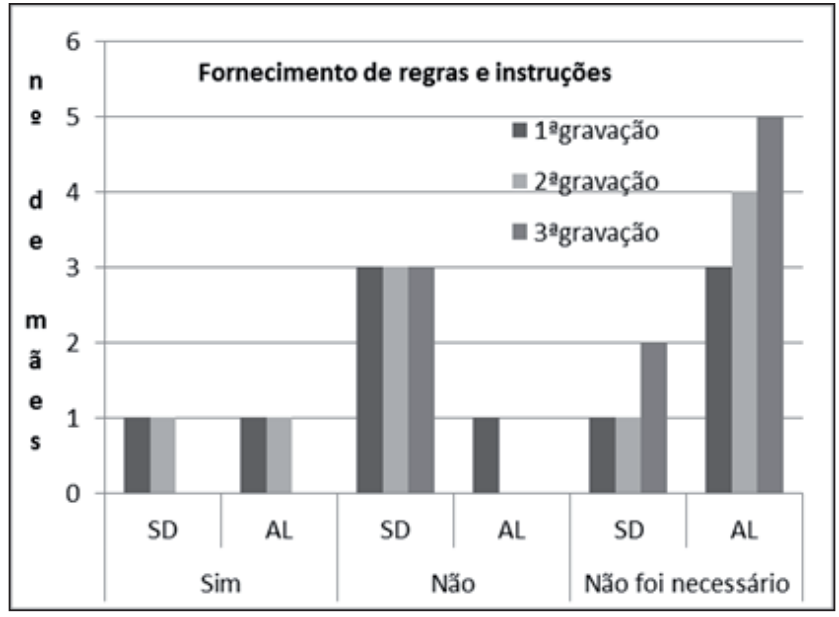

Fonte: própria do autor 
Uma mãe de criança com síndrome de Down e três mães de crianças com alteraçóes de linguagem não precisaram fornecer instrução para a criança, considerando que as crianças já conheciam tais atividades, como mostra a Figura 2 (Compreensão da atividade da criança).

Figura 2 - Compreensão da atividade da criança

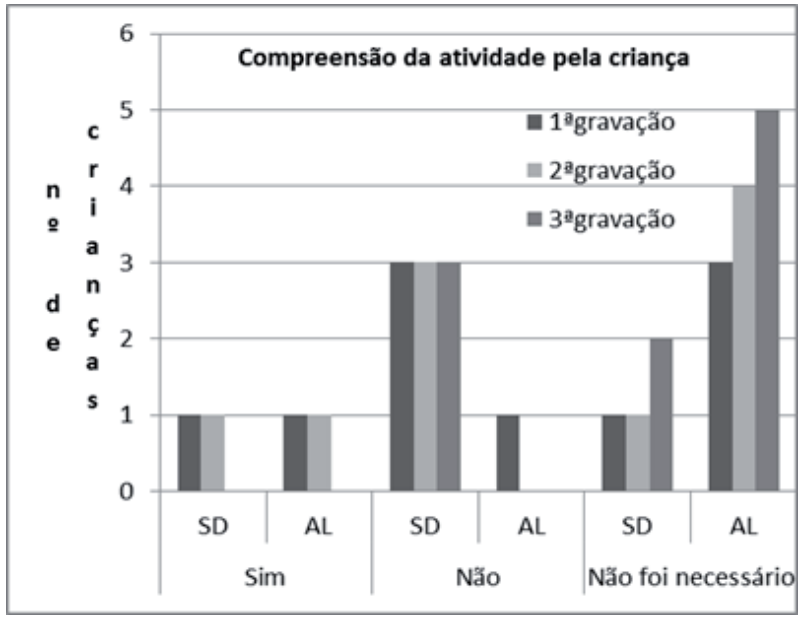

Fonte: própria do autor

Somente uma mãe de criança com síndrome de Down e uma de criança com alteraçóes de linguagem forneceram regras e instruçóes na primeira e segunda gravação. No total das gravaçóes, três mães de crianças com síndrome de Down não forneceram instruçóes claras e objetivas e uma mãe de criança com alteraçóes de linguagem também não forneceu tais instruçóes.

Fornecimento de regras e instruçóes e compreensão das atividades pela criança : A Figura 1 mostra que apenas uma mãe de uma criança com alteraçóes de linguagem em uma única gravação não conseguiu fornecer informação clara que auxiliasse a criança na atividade, em contrapartida três mães de crianças com síndrome de Down não conseguiram passar a informação a seus filhos. Do mesmo modo, três crianças com síndrome de Down nas três gravações tiveram dificuldade em compreender a instrução dada pelo adulto para realização da atividade. Observa-se que crianças com alteração de linguagem não possuem déficits cognitivos, portanto, compreender instruçôes verbais foi mais fácil para elas. Esses resultados mostram que as mães de crianças com síndrome de Down encontram mais dificuldades em fornecer instruçóes que sejam compreensíveis aos filhos.

Limongi (2004) concluiu que a efetividade da interação mãe e criança com síndrome de Down diz respeito a dois fatores: a compreensão das dificuldades da criança e do seu potencial e a compreensão de um processo terapêutico proposto para efetivar essa interação. À medida que as mães melhoram sua interação com seus filhos, estes passam a responder mais e melhor aos estímulos oferecidos e, como consequência, as mães se sentem mais dispostas a estimulá-los. Sendo assim, orientaçóes sobre maneiras de passar informaçóes claras e objetivas que possam 
ser compreendidas pelas crianças deveriam ser oferecidos às mães de crianças com síndrome de Down durante o processo terapêutico.

Interesse: Quanto à categoria que diz respeito ao interesse do adulto em relação à criança notou-se que tanto pais de crianças com síndrome de Down e alteraçóes de linguagem estavam interessados ou muito interessados na atividade proposta; apenas em uma das gravaçóes uma mãe de criança com síndrome de Down estava pouco interessada (Figura 3 - Interesse do adulto na atividade).

Figura 3 - Interesse do adulto na atividade

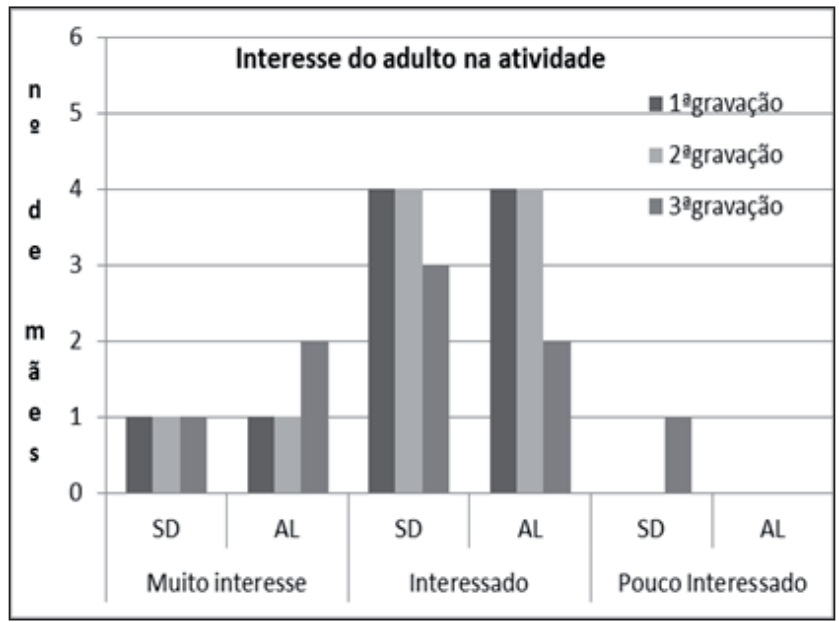

Fonte: própria do autor

O interesse demonstrado pelos pais durante a interação com a criança é uma variável importante, pois não basta a criança ter uma razão para se comunicar e tomar a iniciativa, o adulto deve estar receptivo, atento, sensível aos esforços comunicativos que a criança faz, ou seja, interessado naquilo que a criança tem para dizer (ZORZI, 1999). Isso proporciona condições favoráveis para a interação e, consequentemente, para o desenvolvimento da linguagem.

A Figura 3 mostra que, na primeira e segunda sessão de gravação, uma mãe de criança com síndrome de Down e uma mãe de criança com alteraçôes de linguagem teve muito interesse na realização da atividade e quatro mães de crianças com síndrome de Down e quatro mães de crianças com alteraçóes de linguagem estavam interessadas. Houve mudança apenas na terceira sessão de gravação, em que uma mãe de criança com síndrome de Down mostrou muito interesse, três mostraram-se interessadas e uma mostrou pouco interesse na atividade; já as mães de crianças com alteraçóes de linguagem, uma demonstrou muito interesse e três mostraram-se interessadas nas atividades propostas.

Quanto à Figura 4 (interesse da criança na atividade), na primeira sessão de gravação uma criança com síndrome de Down mostrou muito interesse, três mostraram-se interessadas e uma mostrou pouco interesse; já, das crianças com alteraçóes de linguagem, as cinco mostraramse muito interessadas na primeira sessão de gravação. 
Figura 4 - Interesse da criança na atividade

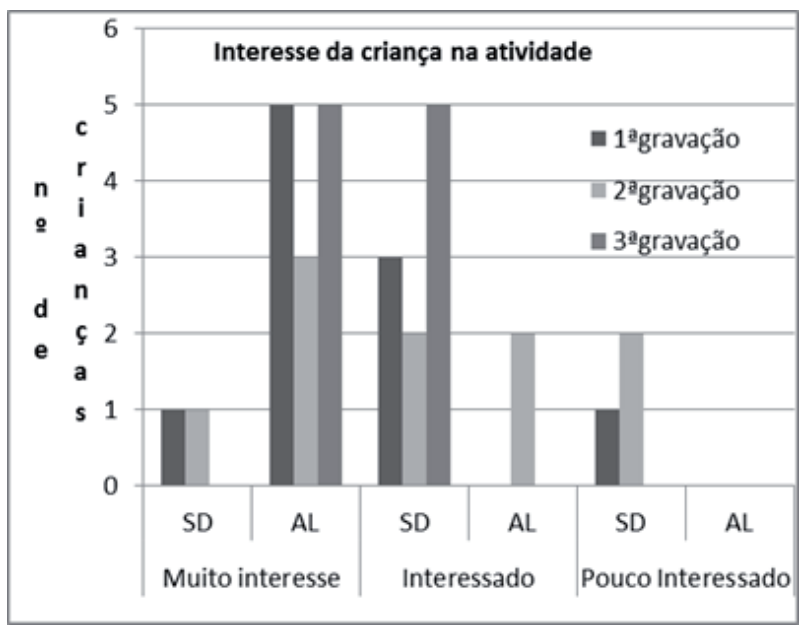

Fonte: própria do autor

Na segunda sessão de gravação uma criança com síndrome de Down mostrou muito interesse, duas estavam interessadas e uma mostrou pouco interesse, enquanto que as crianças com alteração de linguagem três mostraram muito interesse e duas mostraram-se interessadas na atividade. Na última sessão de gravação, as cinco crianças com síndrome de Down estavam interessadas, enquanto três com alteração de linguagem estavam muito interessadas e duas interessadas na realização da atividade. A partir da análise das gravaçóes, percebe-se que crianças com alteração de linguagem demonstraram muito mais interesse na realização das atividades quando comparadas às crianças com síndrome de Down.

Domínio da conversação: Outra categoria interessante de se observar foi o domínio da conversação (Figura 5), visto que no decorrer das três sessóes de interação de pais e crianças com síndrome de Down náo houve mudanças nos resultados.

Figura 5 - Domínio da conversação

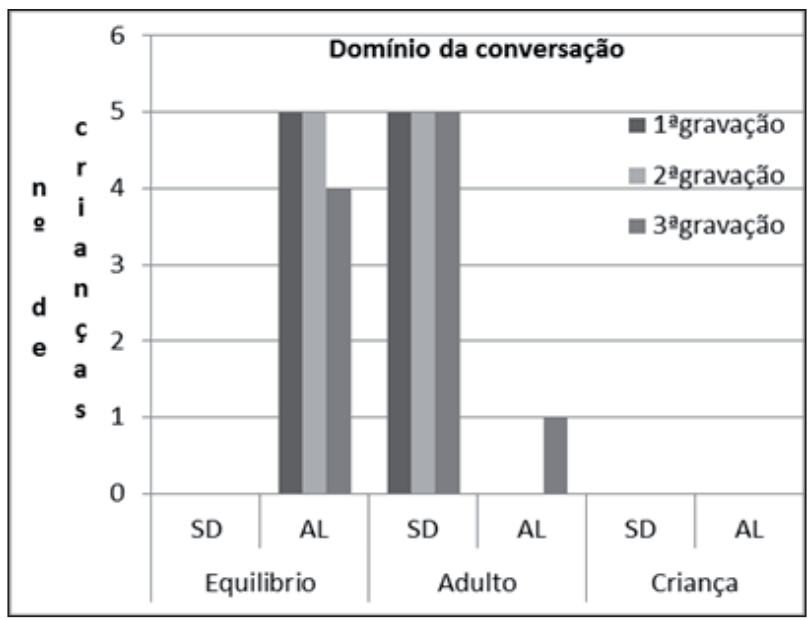

Fonte: própria do autor 
Nas interações de mães e crianças com síndrome de Down, em todas as sessóes analisadas, a mãe foi a pessoa que dominou a conversação. Foi observado que as mães iniciaram mais de 60\% dos tópicos da interação e, em muitas situações, limitaram as possibilidades de respostas espontâneas da criança. Já durante as interaçóes de crianças com alteração de linguagem e seus pais foi observado que, nas duas primeiras gravaçôes, houve um equilíbrio entre interlocutores, ou seja, a díade manteve um equilíbrio, aguardando a vez do próximo para falar e responder. $\mathrm{O}$ parceiro da interação não foi interrompido, souberam ouvir e esperar a vez para falar, aguardavam o parceiro terminar o turno para que pudessem dar continuidade à conversação. Apenas durante a terceira sessão de interação observou-se que, em uma das díades, a pessoa que dominou a conversação foi a mãe. Esses resultados demonstram que mães de crianças com síndrome de Down são muito mais diretivas quando comparadas às mães de crianças com alteração de linguagem, pois diretividade, segundo Zorzi (1999), são atitudes consideradas controladoras: nessa situação o adulto mantém o domínio da conversação, inicia os tópicos da interação, propóem temas e situaçóes, deixando a criança como sujeito passivo durante a conversação. Lopes-Herrera et al. (2009) ainda afirmam que crianças com alteraçóes de linguagem ou com síndromes que de alguma forma comprometam a linguagem podem atuar mais passivamente nesta interação e, assim, podem também afetar o comportamento comunicativo tanto das crianças em relação aos seus pais como dos pais em relação à criança. No caso desse estudo, pais de crianças com alteração de linguagem tiveram comportamentos mais positivos quando comparados aos pais de crianças com síndrome de Down. Os resultados permitem afirmar que, quanto maior o comprometimento cognitivo e consequentemente, de linguagem, mais passiva será a criança durante a comunicação.

Forma discursiva: $\mathrm{Na}$ categoria forma discursiva, envolvendo a análise da estrutura gramatical das díades de crianças com síndrome de Down e seus pais, como esperado, não houve modificação no decorrer das três sessóes. Notou-se que duas mães fizeram uso adequado da forma discursiva, isso quer dizer que usaram frases simples, porém formaram frases gramaticalmente corretas e coerentes, conjugaram verbos, usaram plural de forma adequada, ou seja, essas mães mostraram domínio no uso da língua portuguesa. As outras três mães não mostraram ter domínio das normas da Língua Portuguesa, formaram frases e usaram verbos gramaticalmente incorretos.

Quanto à Figura 6 (forma discursiva do adulto), em todas as gravaçóes a mãe de criança com alteração de linguagem usou a forma discursiva adequada, já duas mães de crianças com síndrome de Down usaram forma discursiva adequada e três usaram a forma discursiva inadequada. 
Figura 6 - Forma discursiva do adulto

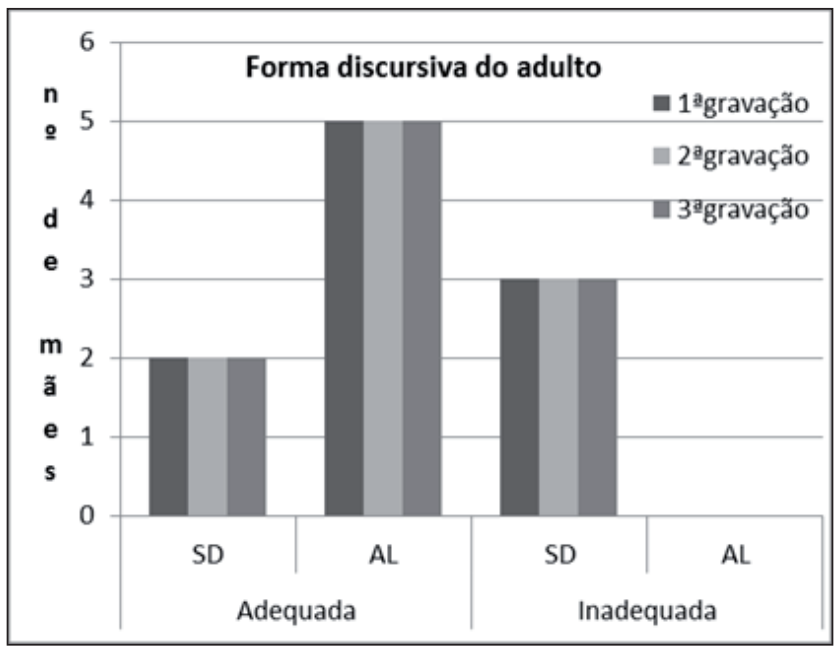

Fonte: própria do autor

No que diz respeito à Figura 7 (forma discursiva da criança), também não houve mudanças no decorrer das três gravaçóes, isso quer dizer que uma criança com síndrome de Down teve a forma discursiva adequada e quatro inadequada, e das crianças com alteraçáo da linguagem, quatro tiveram a forma discursiva adequada e uma inadequada.

Figura 7 - Forma discursiva da criança

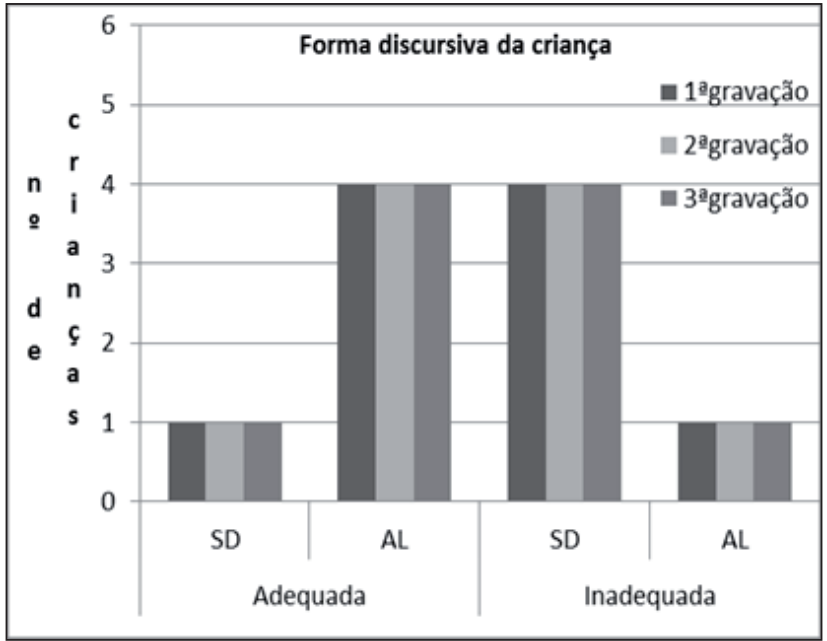

Fonte: própria do autor 
Como no caso das díades de pais e filhos com síndrome de Down, também não ocorreram mudanças na estrutura gramatical dos pais durante as três gravaçôes analisadas, no entanto, nos cinco casos das mães de crianças com alteração de linguagem, as mães usaram a forma discursiva e estrutura gramatical corretamente, formando frases gramaticalmente corretas e coerentes, mostrando domínio no uso da língua portuguesa. Quando se fala da estrutura gramatical, considera-se o nível morfossintático da linguagem, ou seja, a compreensão das regras sintáticas e morfológicas para combinar palavras em frases compreensíveis. A sintaxe ou gramática preocupa-se com a formulação de regras para descrição das formas pelas quais diferentes partes do discurso podem ser legitimamente combinadas para formar frases em uma língua. Nesse estudo, os pais de crianças com alteração de linguagem tiveram um comportamento mais positivo quando comparados aos pais de crianças com síndrome de Down.

Nas três sessões de interação foi observado que quatro crianças com síndrome de Down fazem uso inadequado da forma discursiva, isso significa que elas não conjugam verbos, não usam plural e mostram pouco domínio no uso das normas da Língua Portuguesa. Apenas uma criança mostrou usar a forma discursiva adequadamente. Os resultados das crianças com alteração de linguagem foram contrários aos das crianças com síndrome de Down, pois quatro delas usam a forma discursiva adequadamente enquanto apenas uma faz uso da estrutura gramatical de forma inadequada.

Supondo-se de que há uma relação direta entre desenvolvimento cognitivo e construção da linguagem e de que para que ambas ocorram de forma adequada e efetiva há necessidade de um organismo com suas plenas possibilidades, vivendo em um meio que lhe garanta a realização destas, é claramente delineada a condição de construção de linguagem e de sua expressão na linguagem da criança com síndrome de Down (LIMONGI, 2004). Dessa forma, os resultados corroboram a literatura, pois $80 \%$ das crianças com síndrome de Down demonstraram prejuízo na qualidade da estrutura gramatical, forma discursiva, ou seja, a maioria delas encontra dificuldades para formular sentenças usando corretamente as regras da língua portuguesa.

Complexidade do discurso: Na Figura 8 (complexidade do discurso do adulto), não houve mudança no decorrer das três gravações, ou seja, três mães de crianças com síndrome de Down tiveram o discurso adequado na conversação com seus filhos e duas mães, discurso inadequado, já no que diz respeito às mães de crianças com alteração de linguagem, todas, nas três gravaçóes, usaram o discurso adequadamente. 
Figura 8 - Complexidade do discurso do adulto

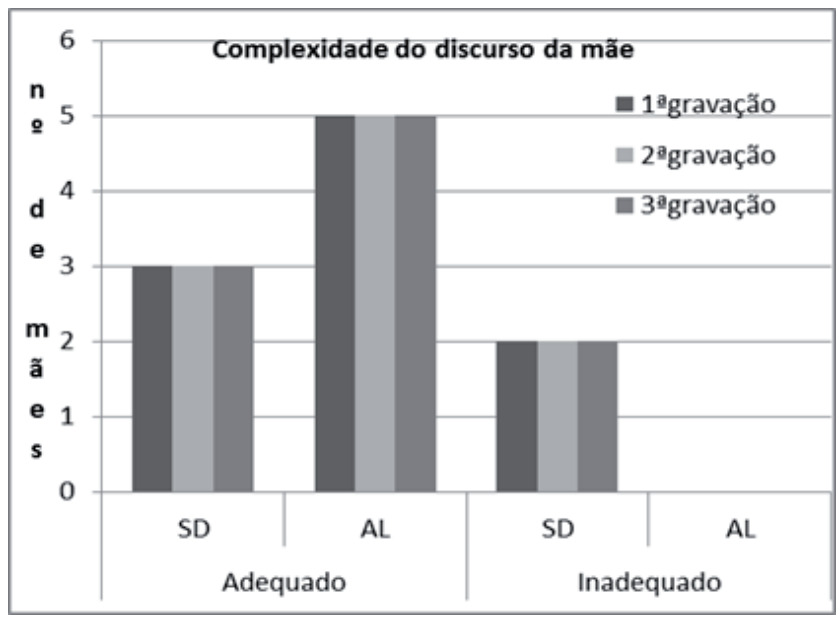

Fonte: própria do autor

As mesmas três mães que fizeram uso adequado da forma discursiva também usaram vocabulário e discurso adequado, ou seja, usaram palavras e expressóes que foram compreendidas pela criança, abordaram temas e situaçóes em que a criança demonstrou compreensão, fizeram uso de temas contextualizados, criando assim oportunidades de diálogo. As outras duas máes fizeram uso inadequado do discurso, sendo que os adultos náo usaram palavras difíceis, no entanto não souberam aproveitar o momento da interação para abordar temas e assuntos contextualizados com a atividade realizada. Não ocorreram mudanças no decorrer das três gravaçôes de crianças com alteração de linguagem e seus pais. As cinco máes de crianças com alteração de linguagem souberam fazer uso adequado do discurso, usando vocabulário pertinente à idade da criança e abordando temas e situaçóes em que a criança demonstrou compreensão, contextualizando o assunto e criando oportunidades de diálogo.

Assim como descrito por Zorzi (1999), os comportamentos dos pais em relaçáo à criança podem ser considerados facilitadores do processo de comunicaçáo e, outros, ao contrário, são considerados controladores durante o processo de interação, ou seja, comportamento que não auxilia a comunicação. Sendo assim, nessa categoria, novamente os pais de crianças com alteração de linguagem demonstraram ter comportamentos mais facilitadores do que os pais de crianças com síndrome de Down, pois procuraram adequar seus níveis de linguagem ao da criança, usando vocabulário nem táo sofisticado, nem demasiadamente simples, além de criarem oportunidades de diálogo. Esses comportamentos auxiliam no processo de desenvolvimento da linguagem da criança.

Técnicas para auxiliar a fala da criança e maneira que a criança reage quando tem a fala corrigida: De acordo com a Figura 9 (técnicas para auxiliar a fala da criança), na primeira sessão de interaçấo de crianças com síndrome de Down e seus pais, observou-se que apenas duas mães usaram um tipo de técnica para auxiliar a fala do filho. 
Figura 9 - Técnicas para auxiliar a fala da criança

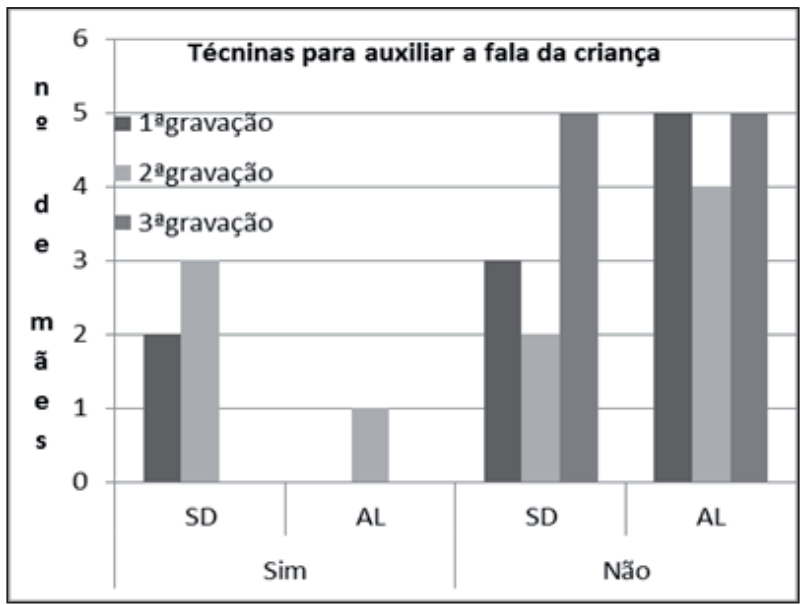

Fonte: própria do autor

Essa técnica, em ambos os casos, foi pedir para criança repetir segundo o modelo fornecido pela mãe. As outras três mães não usaram nenhum tipo de técnica para auxiliar a fala da criança. Na segunda sessão de interação, três mães de crianças com síndrome de Down usaram a mesma técnica, ou seja, pedir para criança repetir a palavra segundo seu próprio modelo. As demais não usaram nenhum facilitador para ajudar a criança a falar as palavras ou frases corretamente. Já na terceira gravação, nenhuma das mães de crianças com síndrome de Down fez uso de técnicas para ajudar a fala da criança. Quanto às mães de crianças com alteração de linguagem, nenhuma usou algum tipo de técnica para ajudar a fala da criança na primeira gravação. Já na segunda sessão de gravação três mães de crianças com síndrome de Down usaram alguma técnica e duas não usaram, das mães de crianças com alteração de linguagem apenas uma usou alguma forma para auxiliar a criança. Na terceira sessão de gravação nenhuma mãe, tanto de criança com síndrome de Down quanto de criança com alteração de linguagem, usou algum tipo de técnica que auxiliasse a fala da criança.

Quanto às crianças, a Figura 10 (forma que a criança reage quando tem a fala corrigida pelo adulto), mostra que na primeira e segunda sessão de gravação duas crianças com síndrome de Down que tiveram a fala auxiliada pelo adulto responderam positivamente, e na segunda sessão de gravação uma criança com alteração de linguagem que teve a fala auxiliada pelo adulto também reagiu positivamente, apenas uma criança com síndrome de Down teve reação negativa na segunda sessão de gravação ao ter a fala corrigida pelo adulto. 
Figura 10 - Forma que a criança reage quando tem a fala corrigida pelo adulto

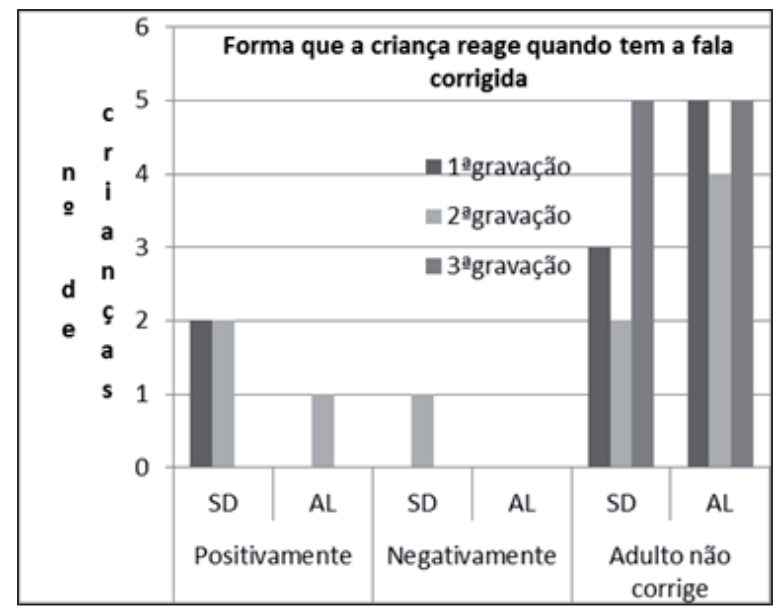

Fonte: própria do autor

Del Prette e Del Prette (2005) destacam que o contexto familiar constitui a base da estimulação inicial dos padróes de relacionamento e competência social. Uma das alternativas que os pais utilizam para promover o repertório socialmente competente dos filhos é o oferecimento de modelos e, na situação desse trabalho, percebe-se que os pais que utilizaram algum tipo de técnica para melhorar a linguagem da criança fizeram uso de seu próprio modelo de fala. Foi possível observar que os pais de ambos os grupos, quando utilizam alguma técnica, fazem uso do mesmo tipo, ou seja, pais de crianças com síndrome de Down e pais de crianças com alteração de linguagem pedem para a criança repetir a palavra segundo modelo fornecido.

Paciência: Na categoria paciência do adulto para com a criança (Figura 11), as mães de crianças com síndrome de Down demonstraram menos paciência para com os filhos, visto que durante a primeira e terceira gravações duas mães demonstraram paciência na maioria das vezes e três em algumas vezes. Na segunda gravação, três mães demonstraram paciência na maioria das vezes e duas em algumas vezes. No que diz respeito às mães de crianças com alteração de linguagem, elas foram mais pacientes com a criança, pois na segunda e terceira gravações as cinco mães foram pacientes com a criança na maioria das vezes. Apenas na segunda sessão de gravação uma das mães foi paciente com a criança algumas vezes. 
Figura 11 - Paciência do adulto para com a criança

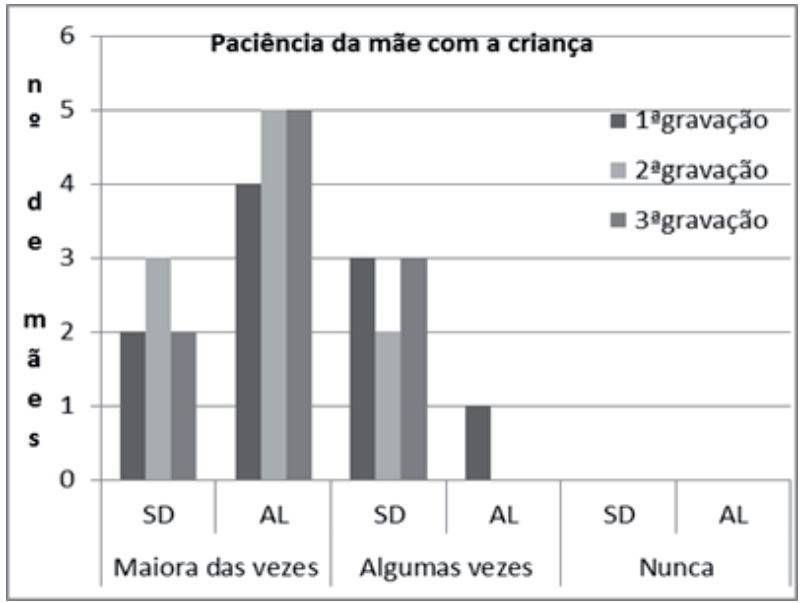

Fonte: própria do autor

De acordo com a categoria aprovada pelas juízas, o adulto demonstra paciência quando sabe ouvir e esperar sua vez para falar, realiza as atividades de maneira que não cause inquietação à criança, não perde a calma, não fala de maneira ríspida, mesmo quando a criança tem algum comportamento que julgam inadequado.

A paciência demonstrada pelo adulto é outra variável importante de se analisar durante o processo de interação, especialmente entre pais e filhos. Nesse estudo, pode-se observar que pais de crianças com alteração de linguagem foram mais pacientes com a criança, ao passo que pais de crianças com síndrome de Down demonstraram menos paciência. Crianças com síndrome de Down se desenvolvem da mesma maneira que outras crianças, porém com limitações de aprendizagem e de desenvolvimento cognitivo, assim como de habilidades sociais e de peculiaridades comportamentais (BISSOTO, 2005). Dessa forma, esse ritmo mais lento de aprendizagem pode ser a condição que faz com que os pais dessas crianças tenham menos paciência com elas. Matsukura et al. (2007) comprovaram, por meio de um estudo, que mães de crianças com necessidades especiais tem um alto nível de estresse, além de poucas pessoas estarem envolvidas em dar apoio e suporte a essas mães, sendo que talvez esse seja um dos motivos pelo qual essas mães têm menos paciência com a criança.

Entonação de fala: No que diz respeito à entonação de fala do adulto (Figura 12), os dados mostram que não houve modificação no decorrer das três sessóes de gravação, ou seja, nas três sessóes, três mães de crianças com síndrome de Down tiveram a entonação de fala adequada e duas inadequada, já das mães de crianças com alteração de linguagem, cinco tiveram entonação de fala adequada no decorrer das sessóes de gravação. 
Figura 12 - Entonação de fala do adulto

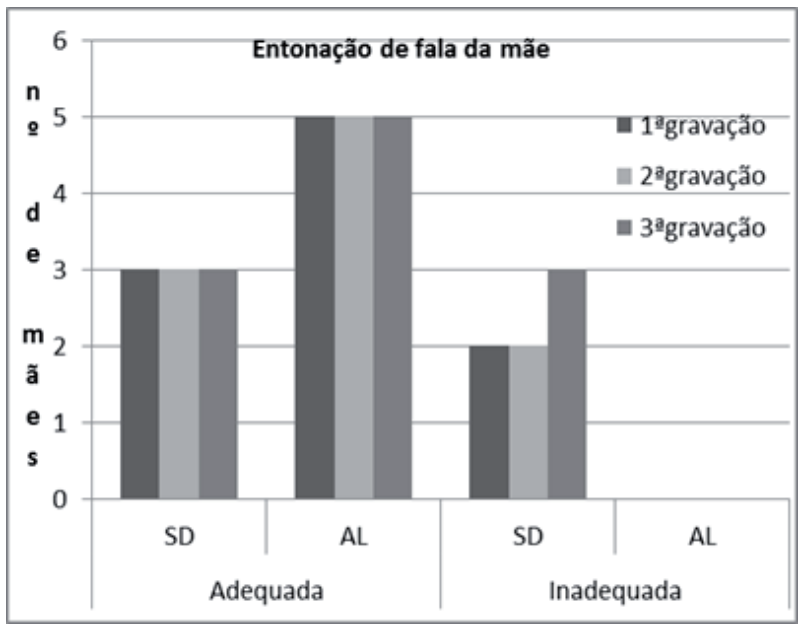

Fonte: própria do autor

Nesse estudo não ocorreram modificaçóes no decorrer das três sessóes de interação no que diz respeito à entonaçáo de fala da criança (Figura 13). Observou-se que duas crianças com síndrome de Down possuem uma adequada entonação de fala e três delas apresentam entonação inadequada, sendo pouco variada, significando que o tom da voz é monótono, sem alteração no ritmo, velocidade e melodia. Como ocorreu no grupo de crianças com síndrome de Down, também não houve modificação no decorrer das três gravaçóes no que diz respeito à entonação de fala das crianças com alteração de linguagem. As três sessóes de observação mostraram que as cinco crianças do grupo com alteração de linguagem possuem adequada entonação de fala, ou seja, possuem ritmo, velocidade e melodia adequados, um tipo de entonaçáo que faz com que o ouvinte participe da conversação.

Figura 13 - Entonação de fala da criança

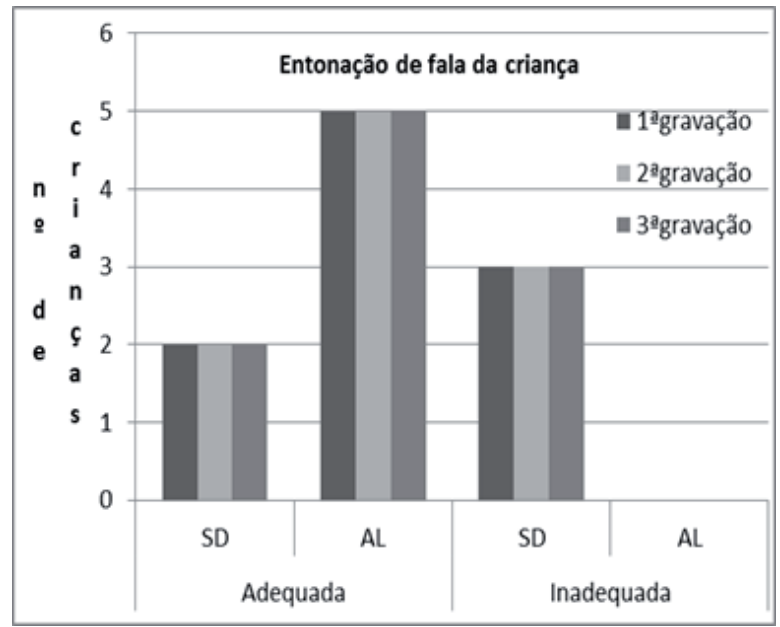

Fonte própria do autor 
A compreensão da comunicação é mais do que apenas entender palavras e frases: ao ouvir um discurso, o ouvinte pode compreendê-lo sem atentar para cada som de palavras. Chega-se ao significado por pistas, pela forma como o conteúdo é colocado e pela entonação da voz do transmissor. Essa capacidade é uma parte importante no entendimento da linguagem (SELIKOWITZ, 2001). Este estudo mostra que três crianças com síndrome de Down possuem entonação de voz monótona, sem alteração no ritmo, velocidade e melodia e, como anteriormente descrito, a entonação de voz do transmissor é um fator importante para que o parceiro da interação se interesse e participe efetivamente da conversação.

\section{Conclusão}

Os dados encontrados no estudo mostram que mães de crianças com alteração de linguagem interagem mais positivamente com a criança quando comparadas às mães de crianças com síndrome de Down. Neste estudo, mães de crianças com síndrome de Down tiveram comportamentos mais passivos, assim como seus filhos.

Os comportamentos destacados como positivos durante a interação de crianças com alteração de linguagem e suas mães, ou seja, aqueles comportamentos que auxiliam o processo de desenvolvimento da linguagem da criança foram: equilíbrio da atividade dialógica durante a interação, estrutura gramatical e complexidade do discurso adequado, mais paciência com a criança e adequada entonação da fala. Já as mães de crianças com síndrome de Down demonstraram maior interesse durante a interaçáo comunicativa e, quando comparadas às mães de crianças com alteração de linguagem, utilizaram mais vezes técnicas que auxiliam a produção de fala da criança.

No que diz respeito às crianças, as com síndrome de Down tiveram mais dificuldades em compreender regras e instruçóes fornecidas pelas mães, demonstraram menos interesse nas atividades, a forma discursiva não foi adequada e a entonação de fala mais monótona.

\section{REFERÊNCIAS}

ANDRADE, C. R. F. et al. Escala das características comportamentais dos pais de crianças fluentes e gagas. Fono Atual, v.27, p.11-20, 2004.

ANDRADE, R. V.; LIMONGI, S. C. O. A emergência da comunicação expressiva na criança com síndrome de Down. Pró-Fono: Revista de Atualização Científica, v.19, n.4, p.387-392, 2007.

BARLOW, D. H.; HERSEN, M. Single case experimental designs: Strategies for studying behavior change. 2. ed. New York: Allyn \& Bacon, 1984.

BISSOTO, M. L. O desenvolvimento cognitivo e o processo de aprendizagem do portador de Síndrome de Down: revendo concepçóes e perspectivas educacionais. Ciências \& Cognição, v.4, n.2, 2005.

BRETANHA, A. C.; LOPES-HERRERA, S. A. Estudo sobre a fidedignidade de dados na avaliação pragmática em crianças com desenvolvimento típico de linguagem. Jornal Sociedade Brasileira de Fonoaudiologia, v. 24, n.3, p. 276-81, 2012.

CASELLI, M. C. et al. Language in Italian children with Down syndrome and with specific language impairment. Neuropsychology, v. 22, n.1, p. 27-35, 2008. 
COMMITTEE FOR CHILDREN AND YOUTHS WITH COMMUNICATION DISORDERS. Inclusive practices. American Speech-Language-Hearing Association, v. 35, n.44, 1996.

DEL PRETTE, A. P.; DEL PRETTE, A. Psicologia das habilidades sociais: teoria e prática. Petrópolis: Vozes, 2005.

FALCONE, E. Habilidades sociais: para além da assertividade. In: R. C. Wielenska (org.). Sobre comportamento e cognição: questionando e ampliando a teoria e as intervençóes clínicas e em outros contextos. Sáo Paulo: Set Editora Ltda, v. 6, 2000.

FERREIRA, A. T.; LAMÔNICA, D. A. C. Comparação do léxico de crianças com síndrome de Down e com desenvolvimento típico de mesma idade mental, Revista CEFAC, v.14, n.5, p.786-79, 2012.

GOMES R. C. G.; ANDRADE, R.V.; LIMONGI, S. C. O. Trabalho de orientação fonoaudiológica a mães de crianças com síndrome de Down (0 a 3 anos): estudo clínico de dois casos, Pró-Fono: Revista de Atualização Científica, v.4, n. 2, p. 22-28, 1992.

HADLEY, P. A.; RICE, M. L. Conversational responsiveness of speech and language impaired preschoolers. J. Speech Hear Research, v. 34, p. 1304-1317, 1991.

LAW, J. Distúrbios da linguagem na criança. Rio de Janeiro: Revinter, 2001.

LEMES, J. M. P.; LEMES, V. A. M.; GOLDFELD, M. Desenvolvimento de linguagem infantil e relação mãe/filho na brincadeira simbólica: a importância da orientação fonoaudiológica. Distúrbios da Comunicação, São Paulo, v.18, n.1, p. 85-94, 2006.

LIMONGI, S. C. O. Linguagem na sindrome de Down: tratado de Fonoaudiologia. SãoPaulo: Roca, 2004. p. 954-966.

LOPES, S. A. Habilidades comunicativas verbais em autismo de alto funcionamento e sindrome de Asperger. 2000. 96f. Dissertação (Mestrado em Educação Especial) - Programa de Pós-Graduação em Educação Especial, Universidade Federal de São Carlos, São Paulo, 2000.

LOPES-HERRERA, S. A. Avaliação de estratégias para desenvolver habilidades comunicativas verbais em individuos com autismo de alto funcionamento e Sindrome de Asperger. 2004. 120p Tese (Doutorado em Educação Especial) - Programa de Pós-Graduação em Educação Especial, Universidade Federal de São Carlos, São Paulo, 2004.

LOPES-HERRERA, S. A. et al. Avaliação comportamental da interação de pais e crianças com alterações de linguagem. In: I SIMPÓSIO INTERNACIONAL DE FISSURAS OROFACIAIS E ANOMALIAS RELACIONADAS; 1; ENCONTRO CIENTÍFICO DE PÓS-GRADUAÇÃO DO HRAC-USP, 8., 2009, Bauru. Anais... Bauru, 2009.

MÄÄTTÄ, T.; TERVO-MÄÄTTÄ, T.; TAANILA, A.; KASKI, M.; LIVANAIENEN, M. Mental health, behavior and intellectual abilities of people with Down syndrome. Down Syndrome Research Practice, v.11, n.1, p.37-43, 2006.

MATSUKURA, T. S. et al. Estresse e suporte social em mães de crianças com necessidades especiais. Revista Brasileira de Educação Especial, v.13, n.3, p. 415-428, 2007.

SCHWARTZMAN, J. S. (Org.). Alteraçôes clínicas. In: Sindrome de Down. São Paulo: Mackenzie, 1999, p. 82-127.

SELIKOWITZ, M. Dislexia e outras dificuldades de aprendizagem. Trad. Alexandre S. Filho. Rio de Janeiro: Revinter Ltda, 2000. 
SILVA, M. F. M. C.; KLEINHANS, A. C. S. Processos cognitivos e plasticidade cerebral na síndrome de Down. Revista Brasileira de Educação Especial, v. 12, n. 1, p. 123-138, abril, 2006.

SYDER, D. Comunicação: alguns conceitos básicos. In: . Introdução aos distúrbios da comunicação. Rio de Janeiro: Revinter, p. 1-25. 1997.

YODER, P. J.; WARREN, S. F. Early predictors of language in children with and without Down Syndrome. American Journal of Mental Retardation. v.109, n.4, p.285-300, 2004.

ZORZI, J. L. Distúrbio da linguagem em crianças pequenas: consideraçóes sobre o desenvolvimento, avaliaçáo e terapia da linguagem. Sáo Paulo: Revinter, 1999.

Recebido em: 02/07/2012

Reformulado em: 27/06/2013

Aprovado em: 02/07/2013 
MAYER, M. G. G.; ALMEIDA, M. A.; LOPES-HERRERA, S. A. 